\title{
US military to sponsor lunar science mission
}

Washington. The US military is preparing to launch a spacecraft to the Moon for the first time since the early days of space exploration, with science along for the ride.

Although the Deep Space Program Science Experiment, nicknamed Clementine, is primarily a test of satellite technology developed for the Pentagon's Strategic Defense Initiative (SDI) programme, scientists involved with the $\$ 80$-million project

\section{IMAGE UNAVAILABLE FOR COPYRIGHT REASONS}

\section{Clementine, with Earth in background, hopes to map lunar surface next winter.}

expect to collect important data at little expense, including the first close-up pictures of an Earth-crossing asteroid. The National Aeronautics and Space Administration (NASA) is providing scientific advice for the mission, to be launched in January 1994.

SDI had planned to orbit a satellite around the Earth to test technology developed for anti-missile satellites, including a lightweight star tracker, battery, sensors and solar panels. But the scope was broadened after former NASA administrator Richard Truly said that his agency should collaborate on a joint programme involving new SDI technology. SDI project managers say that the extra \$30 million being spent to send the spacecraft to the Moon and to an asteroid matches the cost of launching a second spacecraft to be used as a target for testing Clementine's ability to sense an approaching missile.

The spacecraft will enter lunar orbit in late February after flying a series of orbits through different radiation environments surrounding the Earth to meet another SDI objective. For two months it will map the Moon with ultraviolet, visible and infrared sensors from an eccentric orbit that comes within $400 \mathrm{~km}$ of the lunar surface. Eugene
Shoemaker of the US Geological Survey in Flagstaff, Arizona, who heads a 13-member Clementine science team chosen by NASA last month, says the mission will produce a global map of lunar rock types - information that at present exists for only a few scattered sites.

Nearly four months after leaving the Moon, Clementine will fly past the asteroid 1620 Geographos using a new onboard navigation system that automatically adjusts its course in relation

to the asteroid. SDI scientists will have the chance to practise tracking a target, while NASA scientists collect data on the asteroid's shape and surface.

Although the original mission was not a scientific one, Shoemaker and a handful of others helped to select the lunar orbits and the wavelengths for multispectral observation. Shoemaker says that he was chosen both for his experience with lunar and asteroid missions and because he held a security clearance.

It has been 35 years since the US Air Force launched one of the first attempts to reach the Moon, Pioneer 1. Since then, US Solar System exploration has been exclusively the province of NASA, and some scientists are uncomfortable with the idea of teaming up with the military.

Clark Chapman of the Planetary Science Institute in Tucson, Arizona, who has served on several NASA advisory committees for Solar System exploration, would have preferred that the mission be led by NASA and that it should "follow some nationally established scientific goal". The SDI's planning for Clementine has been "very ad hoc", he says, including a hasty selection by NASA of proposed Clementine experiments. Others complain that Clementine gives the Pentagon's missile defence programme a patina of science and that it steals thunder from NASA's own plans to launch a more capable lunar orbiter plans that have languished for a lack of funding.

Shoemaker admits that Clementine was not designed by scientists and that the spacecraft's unproven technology and the ambitious flight plan increase the risk of failure. But he sees it as "a gift" for the planetary science community that may provide valuable data. Even Chapman believes that, in the absence of a NASA lunar exploration programme, "it's better to do something than nothing".
NEWS IN BRIEF

Tokyo. The endless debate about the current ban on commercial whaling is likely to drag on for at least another year. The International Whaling Commission at its annual meeting last week (see Nature 363, 9; 1993) agreed to postpone any action on a revised management procedure that would allow the resumption of commercial whaling in Antarctica and instead voted to establish a working group to report back next year on a French proposal to designate the southern ocean as a whale sanctuary.

D.S.

Munich. Germany's new research minister, Paul Krüger, intends to start negotiating immediately for more research money in next year's budget. Reserved and cautious, Krüger has declined to announce his priorities until he analyses the political situation, but he has promised to maintain the policies of his predecessors. He is expected to be particularly supportive of additional funding for east Germany which, he says, "provides only 2.5 per cent of Germany's innovative exports, despite the available potential".

A.A.

New Delhi. The Indian government is investigating a fire earlier this month that destroyed three floors of the country's leading medical research institute. The fire at the all-India Institute of Medical Sciences in New Delhi wiped out years of results on two dozen major research projects, as well as ruining equipment and killing experimental animals. One biochemistry laboratory supplied reagents, antibodies and cell lines to researchers throughout India. Although the institute expects to receive funds to rebuild the facility and replace lost equipment, researchers blame management for having failed to install such basic precautions as alarms, smoke detectors and sprinkler systems.

K.S.J.

London. The Japanese pharmaceutical company Eisai has promised to invest more than $\mathrm{E} 60$ million (US $\$ 90$ million) over the next 15 years in a new laboratory opened last week at University College, London (UCL). The laboratory will focus on the molecular and cell-biology aspects of the neurosciences, in particular diseases such as stroke, Parkinson's, multiple sclerosis and Alzheimer's. Derek Roberts, the provost of UCL, points out that the college's links with Japan stretched back to 1863 , when four Japanese undergraduates - one of them a future primeminister - came to London to study analytical chemistry. The two-year-old agreement has already resulted in $£ 14$ million being spent on a new research building that will eventualiy become part of the college.

D.D. 